\section{AKADEMOS}

Órgano de difusión de la Red Docencia-Investigación

ISSN: 1995-4743

Año 14 Vol. 2, n. 35 Julio-Diciembre 2020

\section{Año 14 Vol. 2, n. 35 Julio-Diciembre 2020}

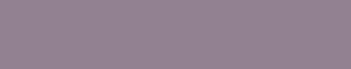

AKADEMOS es una revista semestral. De amplio espacio editorial, para la publicación de trabajos inéditos de investigación, artículos de análisis, reseñas y opinión, en los distintos tópicos de las ciencias, la tecnología, las artes y la cultura.

\title{
El Salvador: Déficit fiscal, Covid-19 y Crecimiento
}

Mauricio González Orellana

Licenciado en Economía e Investigador del Centro de Investigaciones

en Ciencias y Humanidades, CICH de la Universidad Dr. José Matías Delgado

mgonzalezo@ujmd.edu.sv

\section{Introducción}

Hace años que en el país el tema del déficit fiscal domina el debate económico en los medios. De vez en cuando, se tocan otros temas como las remesas y las pensiones, pero su rating no se compara con el del déficit fiscal. Con frecuencia se mencionan informes amenazantes, como cuando las calificadoras de riesgo alertan sobre un alza en el riesgo país en relación con las tasas de interés que el Gobierno ha de pagar por más endeudamiento, interno y externo, o que ya se topó "la tarjeta de los bancos" para comprar más LETES.
Es posible que en 2021 el déficit fiscal se acerque al 10\% del PIB, y la deuda total se acerque al 100\% del PIB; incluso podrían sobrepasar estos porcentajes. Normalmente estas cifras se consideran alarmantes, especialmente para una economía pequeña, y la discusión para atenuar sus impactos suele girar en torno a las acciones por las que se aumentan o se disminuyen los impuestos y/o los gastos del Estado.

Los gastos asociados a la pandemia han intensificado las referencias a los peligros y presiones derivados del déficit fiscal y la deuda pública, y una vez más han llegado a 
ser el tema preferido en el debate económico del país. En este artículo se señala que, sin embargo, este no es el problema económico más importante de El Salvador, sino, más bien, una manifestación solamente de un problema más serio, la falta de crecimiento económico. Por la misma razón, se muestra que la solución para el déficit fiscal pasa primero por resolver el problema sanitario creado por la pandemia, el del desempleo, la migración, y la recuperación económica; a partir del logro de un crecimiento económico sostenible e inclusivo.

\section{Sobre el déficit fiscal y el gasto público en tiempos del Covid-19}

Antes que nada, cabe mencionar que en el mundo los gobiernos enfatizan dos aspectos en su manejo de la crisis del Covid-19: una etapa de emergencia y otra para la recuperación económica; la primera suele contar con dos elementos, siendo el primero un trato prioritario de la emergencia sanitaria en la que se pretende el fortalecimiento de los sistemas de salud, y el segundo la aplicación de un programa de asistencia a la población que suele consistir de un ingreso básico universal y/o un programa de empleo como el de un empleador de última instancia.

Por otro lado, en un país como el nuestro, es necesaria una tercera etapa en la que el objetivo básico es el del logro de un crecimiento inclusivo sostenido en el tiempo. Aquí se llamará al conjunto de las tres etapas un Plan Económico. Luego, tomar en cuenta que la preocupación por el déficit fiscal no debe ser a tal grado que las accio- nes para llevarlo a niveles sostenibles terminen por llevar al abismo la recuperación, dada su naturaleza claramente reductora del empleo y el PIB. Se recuerda que la recuperación es intensiva en el uso de recursos financieros, como lo son en conjunto las etapas 1 y 2 del Plan Económico.

$\mathrm{Al}$ respecto, es probable que algunos analistas propongan una consolidación fiscal -es decir, una reducción importante del déficit fiscal- "tan pronto como sea posible", quizás este año o el próximo, aduciendo que el problema fiscal es una "bomba de tiempo", y que su desatención conduciría a una "colisión catastrófica", dados los niveles de endeudamiento y déficit fiscal actuales. Sin embargo, esta preocupación pasa por alto que una bomba de mayores dimensiones que la fiscal empezó a explotar a principios de los 2000, por razones que se explican luego, y que ha seguido haciendo estragos desde entonces. Cualquier cosa que suceda de 2021 en adelante puede verse como una secuela de lo que empezó con el nuevo milenio.

La explicación: cuando se conduce un coche de forma que se exceden sus parámetros de funcionamiento, el vehículo fallará en algún momento, por ejemplo, con frenos sobrecalentados, exceso de velocidad, o falta de combustible. El coche es un sistema en funcionamiento y si sus restricciones se exceden falla. Esto pasa con una economía; se trata de un sistema cuya operación requiere respetar ciertas restricciones para que funcione bien de forma permanente. Si estas se exceden el sistema puede reventar como una bomba, y el estallido es uno que puede durar años. 
América Latina es el prototipo de esta clase de episodios que la literatura y la historia económicas han llegado a denominar como "crisis, boom y ajuste" o "sudden stop", que resultaron en desempleo, inflación, caídas del PIB, crisis financieras, cambiarias, de balanza de pagos, etc., actuando como válvulas de escape. En general, estas válvulas suelen dejar de operar a los 5 años. En el país, las válvulas de escape principales son de fácil identificación: delincuencia, subempleo y migración; y llevan más o menos dos décadas operando. Estas válvulas pueden ampliarse y empeorar con el agudizamiento del problema fiscal; incluso, pudieran aparecer otras válvulas, como un empeoramiento de los niveles de pobreza; quizás a los niveles de algunas economías africanas.

Conviene mencionar que el caso salvadoreño no es del tipo de auge y caída que caracterizó a varios países latinoamericanos en la segunda mitad del siglo pasado. En muchos de tales países el entorno político y social era muy volátil dificultando el éxito de cualquier modelo de desarrollo. No es el caso de El Salvador de hoy; al menos no tiene la gravedad de aquellos episodios todavía; pero la crisis del país no había terminado antes de la pandemia, y mientras aquellos países han terminado en alguna clase de recuperación, El Salvador no solo no ve un final para sus graves problemas, sino que el Covid-19 los ha magnificado. Peor aún, no se conoce un programa económico que delinee la salida.

Por otro lado, es al menos llamativo que ante los problemas desatados por la pandemia -los de endeudamiento y déficit fiscal princi- palmente- entes como la CEPAL y el FMI enfatizan la importancia de utilizar los espacios fiscales que tengan los países para apoyar los primeros dos componentes que hemos incluido en el Plan Económico de tres componentes que hemos sugerido. De hecho, otros entes como el Banco Central Europeo, BCE, han sugerido que se gaste "lo que sea necesario" para atender el financiamiento de aquellos componentes. Otros han mencionado que "este no es tiempo para preocuparse de un déficit fiscal" y que ya habrá tiempo para eso "el día después". Nótese el contraste entre las prescripciones que para el déficit fiscal se advierten en los medios noticiosos del país, y los del FMI, CEPAL y BCE.

El énfasis en "lo que sea necesario", desde luego, no es antojadizo, ni tampoco la recomendación de "usar todo el espacio fiscal". Existen fuertes antecedentes históricos $\mathrm{y}$ analíticos que respaldan tales recomendaciones. Para comenzar, estas no son nuevas; tanto en EE. UU. como en Europa se llevaron a la práctica por parte de la Fed (banco central de EE. UU.) y el BCE, a partir de los famosos "quantitative easing" o relajamientos cuantitativos -gasto fiscal masivo de billones de dólares para apoyar el aumento de la demanda agregada-, en ocasión de la Gran Recesión, GR, de 2008/9. ¿Cuál es el origen de esta forma de abordar los gastos asociados al manejo de una mega crisis?

\section{La Gran Depresión: las lecciones aprendidas}

La recomendación del gasto fiscal masivo para prevenir los efectos más nefastos de 
una crisis como la actual puede asociarse con el manejo macroeconómico por parte de muchos países del que ha llegado a ser considerado como el referente más importante de este tipo de fenómenos: la Gran Depresión, GD, de los años 1930, es decir, hace casi un siglo. Este episodio de la historia económica universal es probablemente el más fascinante y estudiado por los macroeconomistas que buscan conocer sus causas y consecuencias, así como la manera en que se superó, para derivar lecciones valiosísimas que pudieran aplicarse a crisis posteriores. De hecho, alguien dijo que "la Gran Depresión es para la economía lo que el Big Bang es para la física" (Margo (1992)).

Las lecciones que se van a considerar, a su vez, se han aplicado en -y también derivado de- otras crisis, como la economía de guerra que adoptaron muchos países en ocasión de la $1 \mathrm{GM}$ y $2 \mathrm{GM}$, en la que la mayoría de recursos se dedica al esfuerzo bélico; o en el caso de una catástrofe natural que devasta una amplia región o un país entero. En estos casos lo más común es que las formas convencionales de hacer política económica se hacen a un lado; por ejemplo, ante la necesidad imperiosa de recursos, los países suelen incurrir en déficits fiscales que luego monetizan mediante la impresión de dinero.

En lo que sigue, el lector hará bien en recordar 1) el problema fiscal de El Salvador al hablar de expansión monetaria, y 2) la dolarización al hablar del sistema cambiario vigente durante la GD. Nuestra perspectiva al abordar la crisis provocada por la pandemia es que se trata de lo peor que ha debido confrontar el género humano en su historia, con la única excepción del diluvio del Génesis.

Al considerar las causas de la GD, obviamente, las identificadas han variado según la corriente económica de la que procedan los investigadores -distinguiendo especialmente entre keynesianos, monetaristas, y heterodoxos-, pero hay una de aceptación prácticamente universal: la falla de los bancos centrales y otras agencias asociadas en el manejo macro de una crisis en flexibilizar la política monetaria -entre otras cosas, aumentando la oferta monetaria, sea por la compra de deuda del Gobierno o mediante la impresión de dinero- para apoyar la recuperación de la demanda agregada de manera que esta impulse el aumento de la oferta agregada y con ello la reanudación de la actividad económica, el empleo y el crecimiento.

Detrás de los aspectos monetarios se hallan otros factores, sin embargo. Bernanke, uno de los estudiosos más conocidos de la GD examina sus causas, y explica en Bernanke (1995) que

Desde temprano en los $1980, \ldots$ un nuevo cuerpo de literatura sobre la Depresión ha surgido y se enfoca en la operación del patrón oro en el período entreguerras. ... De manera sustancial -en claro contraste con el estado inconcluso de estos asuntos que prevaleció a fines de los 1970- la nueva investigación sobre el patrón oro nos permite afirmar con mucha confianza que los factores monetarios jugaron un papel causal importante, tan- 
to en la caída de precios y producción en todo el mundo como en su eventual recuperación. Dos aspectos bien documentados apoyan esta conclusión.

En el primero de estos hace referencia a una relación entre el patrón oro -es decir, el sistema de tipos de cambio fijos de antes y después de la primera guerra mundial y después de la segunda- y la contracción monetaria de principios de los 1930; y en el segundo explica que

... por razones de índole histórica, política, y filosófica, más que puramente económicas, algunos gobiernos respondieron a la crisis de principios de los 1930 abandonado enteramente el patrón oro, mientras que otros escogieron permanecer en éste a pesar de las condiciones adversas. Los países que dejaron el patrón oro fueron capaces de reflotar sus ofertas monetarias y elevar sus niveles de precios, ... los países que siguieron con el patrón oro se vieron impulsados a una mayor deflación. De forma abrumadora, la evidencia muestra que los países que dejaron el patrón oro se recuperaron de la Depresión más rápidamente que los países que siguieron con este. De hecho, ningún país mostró una recuperación económica significativa mientras siguió con el patrón oro. La fuerte dependencia de la tasa de recuperación de la elección del régimen cambiario es, además, una poderosa evidencia de la importancia de los factores monetarios.

Notamos el énfasis de Bernanke (1995) en "los factores monetarios" para explicar las causas de la GD; pero ahora es necesario retroceder un eslabón en su cita; lo que hizo que los factores monetarios incidieran de la forma en que lo hicieron fue la misma en todas partes: el patrón oro. Esto también se advierte de Eichengreen y Temin (2010):

En este ensayo describimos por qué el patrón oro y el euro son formas extremas de tipo de cambio fijo, y cómo estas políticas tuvieron sus efectos más potentes en los peores períodos económicos de paz de los tiempos modernos. Si bien tenemos la suerte de haber evitado otra catástrofe como la Gran Depresión en 2008-9, en virtud principalmente del uso agresivo de los estímulos monetarios y fiscales por parte de los formuladores de política, la economía todavía está experimentando muchas dificultades. Como en la Gran Depresión, esta segunda ronda de problemas se derivan de la prevalencia de tipos de cambio fijos. Los tipos de cambio fijos facilitan los negocios y las comunicaciones en los buenos tiempos, pero intensifican los problemas cuando los tiempos son malos. (Abstract, subrayado agregado)

No preguntamos ni intentamos responder si la adopción generalizada del patrón oro a mediados de la década de 1920 o la creación del euro en 1999 fueron decisiones equivocadas. Ambas reflejaron fuerzas históricas profundamente arraigadas que se desarrollaron durante largos períodos de tiempo: un conjunto de convenciones sobre el patrón oro y una mentalidad que floreció en el siglo XIX, permitiendo que el patrón oro fuera visto como la base normal para las operaciones monetarias 
internacionales; y un proceso de integración europea con raíces que se remontan mucho antes de la Segunda Guerra Mundial y que floreció plenamente en el fértil semillero que fue la segunda mitad del siglo 20. Tomamos estas circunstancias profundamente arraigadas como dadas y preguntamos cómo podrían haberse manejado mejor. Preguntamos, en particular, si podrían haber sido manejadas para prevenir el desastre económico.

El patrón oro se caracterizó por el libre flujo de oro entre individuos y países, el mantenimiento de valores fijos de las monedas nacionales en términos de oro y por lo tanto entre sí, y la ausencia de una organización coordinadora internacional. Juntos, estos arreglos implicaron que había una asimetría entre los países que experimentaban déficit en la balanza de pagos y los que tenían superávit. Hubo una penalización por quedarse sin reservas ( $\mathrm{y}$ no poder mantener el valor fijo de la moneda), pero ninguna penalización (aparte de los intereses perdidos) por acumular oro. El mecanismo de ajuste para los países deficitarios fue la deflación en lugar de la devaluación, es decir, un cambio en precios internos en lugar de un cambio en el tipo de cambio.

Este último punto, la elección de la deflación sobre la devaluación, se puede ver claramente ahora como el nadir de la Depresión. (Pgs. 1 y 2)

En otras palabras, lo que sucedió fue que los bancos centrales se retuvieron de dirigir recursos para 1) rescatar bancos -solo en
EE. UU. quebraron miles de bancos en el período más doloroso de la GD-; 2) rescatar empresas pequeñas, medianas y grandes para mantener el empleo y la producción; y 3) apoyar a desempleados y sus familias mediante el "dinero arrojado de un helicóptero" obtenido en general de la impresión de dinero por parte de la autoridad monetaria -algo parecido, pero no igual, a los $\$ 300$ que se entregaron a algunas familias al principio de 2020 en el país.

Entonces, los bancos centrales de los países en que azotó la GD provocaron -tal vez inadvertidamente; pero no siempre- la profundización de la GD al ejercer una política monetaria endurecida e inflexible ante el fenómeno. Nótese, desde luego, que para la pandemia todos los países están haciendo exactamente lo contrario, es decir, están apoyando primordialmente a sus sistemas sanitarios -que han colapsado en varios países- por tratarse de la primera línea de defensa contra el virus, así como a los desempleados y sus familias para satisfacer sus necesidades básicas -incluso con el "dinero de helicóptero"-, y a bancos y empresas; esto muestra que, en general, las lecciones se han aprendido.

Esto también se está haciendo en El Salvador; se ha apoyado al sistema de salud, a familias y empresas; solo que de una forma demasiado limitada; las necesidades de financiamiento siguen aumentando, y las tarjetas de crédito interno y externo del país parecen haber llegado a sus límites. El déficit fiscal y la deuda pública siguen aumentando, y la preocupación por esto es 
legítima. Sin embargo, ante la escasez de recursos cabe preguntarse por cuáles serán las prioridades: ¿es más apremiante el pago de la deuda a los bancos que la compra de vacunas y el apoyo a los desempleados y sus familias? Este país no es el único que se ha visto ante disyuntivas como esta. $\mathrm{Y}$ en varias ocasiones, la disyuntiva se ha resuelto a favor de las acciones sociales, degradando la importancia del déficit fiscal y la deuda.

Eichengreen y Temin explican también algunas nociones fuertemente arraigadas en aquella época, y aun ahora, como la de que la manera de ajustarse ante el déficit externo debe ser la de la flexibilidad hacia abajo de los salarios, en un proceso que también abate a los precios, la deflación. Muchos pensarían que la deflación sería bienvenida, por su carácter contrapuesto al de la inflación, pero hay que decir que ambos fenómenos pueden ser igual de destructivos. Si acaso, para muchos, la deflación es peor. Regresamos a esto adelante para El Salvador.

Por otro lado, no se trata de problemas que ocurrieron en un tiempo relativamente lejano y que si ocurrieran ahora los tomadores de decisiones sabrían cómo tratarlos. Como se verá, los tipos de cambio fijos han de fracasar más o menos estrepitosamente si no se dan las condiciones necesarias para su buen funcionamiento: que los países del centro poseedores del oro o las divisas que operan como monedas de reserva estén dispuestos a ceder de alguna manera parte de sus reservas a los países periféricos que registren déficits externos para mantener la estabilidad del sistema monetario internacional. Por lo demás, hay que decir que ahora estas condiciones simplemente no existen, y que lo común son los tipos flotantes y los manipulados, al menos entre los países desarrollados y buen número de emergentes.

En su momento, Estados Unidos e Inglaterra, con el dólar y la libra esterlina, eran los países del centro que proveyeron por un tiempo las reservas que necesitaban los países periféricos; pero después, EE. UU. en 1933 e Inglaterra en 1931, estuvieron entre los primeros países que dejaron el patrón oro para poder revertir los efectos de la GD en sus propias economías; otros países lo hicieron a lo largo de los 1930.

La estabilidad del sistema monetario internacional fue un hecho en algunos períodos, y el sistema del patrón oro funcionó. Fue solo cuando fenómenos como la 1GM y la 2GM hicieron su aparición, que la coordinación del sistema se vino para abajo; y la mayoría de países dejó el patrón oro, al dar prioridad a sus problemas domésticos y desentenderse de los problemas de otras economías. En ocasiones se ha dicho que factores de índole sicológica parecen explicar una especie de fascinación por el sistema de tipos fijos, que a su vez parece explicar en parte al menos otro intento a su favor a partir de los acuerdos de Bretton Woods después de la 2GM. El derrumbe ocurrió de nuevo cuando el presidente Nixon de EE. UU. eliminó la convertibilidad del dólar por oro en 1971.

Como se ha visto, el abandono del patrón oro allanó el camino para la política mone- 
taria expansiva, el aumento de la demanda y oferta agregadas, los precios -la inflación moderada fue bienvenida-, y el empleo. Es probable que el caso más emblemático de una recuperación sólida a partir del abandono del patrón oro, y las consiguientes devaluación y expansión monetaria, lo constituya el conjunto de reformas que se llevaron a cabo en EE. UU. durante los 1930, ampliamente conocido como el New Deal del presidente Roosevelt.

La crisis desatada por el Covid-19 se maneja de forma consistente con las lecciones aprendidas por varios países como EE. UU., Inglaterra, Japón y Australia, donde el monto del gasto público se lleva a cabo con el criterio de "cueste lo que cueste", sin dejar de mencionar que sus tipos de cambio no son fijos sino flotantes.

Por otro lado, para algunos países desarrollados la aplicación de estas lecciones no ha sido inmediata y no ha estado exenta de serios obstáculos. Es el caso del sistema del euro. El lector quizás diga que el euro no es un tipo de cambio fijo porque flota libremente en los mercados internacionales, y tiene razón. Pero el problema al que nos referimos no es el del euro vis á vis las otras monedas, sino al problema que su construcción reviste para los países que participan del sistema y buscan encarar su estancamiento y ahora el empeoramiento causado por el Covid-19. Ninguno de los países de la zona del euro ${ }^{1}$-Alemania, Francia, Italia y España, por ejemplo-, puede por sí solo llevar a cabo una flexibilización cuantitativa, imprimir dinero o efectuar una devaluación. Note el planteamiento de Eichengreen y Te$\min (2010)$

El patrón oro fue preservado por una ideología que indicaba que solo bajo condiciones extremas podría dejar de ser fijo. Pero el euro ha dado un paso adicional, al eliminar las monedas nacionales. Modificar unilateralmente el régimen de políticas es incluso más difícil que bajo el patrón oro. Si bien es concebible, en teoría, que un miembro titular de la zona del euro podría optar por reintroducir su moneda nacional y depreciarlo frente al euro, no hay ninguna disposición para hacerlo en el Tratado de Lisboa. Del mismo modo, es concebible que un miembro titular pueda optar por hacer caso omiso de sus obligaciones en el tratado. Pero, incluso entonces, si la decisión de reintroducir la moneda nacional y convertir todos los activos y pasivos financieros de los residentes a esa moneda no se hace instantáneamente, seguiría un período de extrema inestabilidad financiera, ya que los inversores retirarían su

1 En los portales de la UE se puede verificar que los países que actualmente forman parte de la zona euro son: Alemania, Austria, Bélgica, Chipre, Eslovaquia, Eslovenia, España, Estonia, Finlandia, Francia, Grecia, Irlanda, Italia, Letonia, Lituania, Luxemburgo, Malta, Países Bajos y Portugal. Hoy en día, el euro ( $€$ ) es la moneda oficial de 19 de los 27 países miembros de la UE, que juntos constituyen la eurozona, denominada oficialmente zona del euro. El Tratado de Lisboa, que entró en vigor a finales de 2009, confirió nuevas competencias legislativas al Parlamento Europeo y lo puso en pie de igualdad con el Consejo de Ministros para decidir qué hace la UE y cómo se gasta el dinero. 
dinero del sistema bancario y financiero nacional en masa, creando lo que uno de nosotros ha llamado "la madre de todas las crisis financieras" (Eichengreen 2010). (Pg. 3)

Para un mejor entendimiento de lo que sucede en la zona del euro comencemos diciendo que los países que la conforman (19 en la actualidad) tomaron la decisión de renunciar a sus monedas nacionales y adoptar una común, el euro. Esto significa, entre muchas otras cosas, que no pueden ejercer una política monetaria propia, por la que puedan emitir dinero o aumentar su oferta monetaria de manera de atender alguna señal de recesión que impida que luego se convierta en depresión, a menos que se lleve a cabo una acción conjunta a partir del $\mathrm{BCE}$ que es el único que puede emitir euros, y que practica una política monetaria común para toda la zona euro.

Pero también significa que no pueden ejercer una política cambiaria activa -la otra cara de no tener una política monetaria propiapor la que puedan depreciar una moneda nacional frente a las del resto de la zona y compensar así diferencias de competitividad que a su vez les permita que sus déficits externos se reduzcan a los niveles permitidos por los tratados europeos de manera de mantener la estabilidad al interior de la zona euro. El lector no debe pensar que las depreciaciones cambiarias son cosa de países en desarrollo solamente, que los países desarrollados tienen tipos flotantes y por esto no necesitan depreciarlas.
En realidad, el nivel de la flotación puede ser impulsado hacia arriba (depreciando la moneda) a partir de la flexibilización cuantitativa, tanto con el dólar como con el euro, cosa que efectivamente ha sucedido, lo cual motivó una protesta más o menos airada por parte de un ministro de finanzas brasileño que se quejó y acusó a EE. UU. de desatar una "guerra de divisas" contra las economías emergentes que habían operado depreciaciones de una forma más explícita para dotar de mayor competitividad a sus exportaciones, especialmente en los mercados norteamericano y europeo. Esto, porque las depreciaciones del dólar y el euro anulaban en buena parte el aumento de competitividad que países como Brasil habían conseguido al depreciar sus monedas. Recuérdese que después de todo, para muchos países en el caso de la GD, la devaluación/depreciación fue clave para el proceso de recuperación una vez se dejó el patrón oro.

Esta circunstancia, la necesidad de mayor competitividad y por esto de ajustes cambiarios para corregir los desequilibrios externos aumentando las exportaciones, ha sido y sigue siendo critica para países como Italia, España y Grecia -países "derrochadores"- frente a socios como Alemania y Holanda -países "frugales"- porque cuando los "derrochadores" han solicitado la asistencia del BCE para atender sus problemas internos de baja productividad y desempleo, los "frugales" se han opuesto a menos que se acepten una serie de condiciones de índole empobrecedora que son típicas de los stand by del FMI. 
Y es que al interior de la zona euro, el lector notará, priva un sistema de tipos de cambio estrictamente fijos -como los países del patrón oro antes de la GD-, y en última instancia la única manera de romper esta atadura es saliéndose del euro -como lo hicieron los países al dejar el patrón oro para atajar los impactos de la GD-, lo que, como se notó de Eichengreen y Temin (2010), tiene sus propias complicaciones: en la actualidad, $\underline{\underline{y}}$ en el contexto de la zona monetaria europea, podría desatar "la madre de todas las crisis financieras", al interior de la zona y con repercusiones en el resto del mundo, porque no se habla de cualquier país, sino de Euro$\mathrm{pa}$; entre otras razones, porque si algunos países lo hicieran, los demás tendrían un incentivo para hacer lo mismo y entonces se derrumba el sistema.

El caso de Grecia en la solución a sus problemas de endeudamiento y su traumática confrontación con "la Troika" en el contexto de la zona euro, ilustra este y muchos otros defectos que se hallan en la construcción del sistema del euro, y se hallan en la base de algunas de las críticas más potentes que se han formulado contra su configuración; por ejemplo, que la unión monetaria debe ser complementada por una unión fiscal y una unión bancaria. En los casos de España, Italia y Grecia, los llamados a dejar la UE han sido frecuentes.

Ahora bien, aunque a nivel de los países del euro parece que las lecciones de la GD no

Formada por la Comisión Europea, el FMl y el BCE. se han aprendido, o al menos no se han aplicado, la buena noticia es que el BCE sí lo ha hecho, aunque para ello ha debido fracturar algunos de los preceptos fundamentales en los que se ha levantado el edificio europeo y ha debido confrontar con oponentes poderosos como el Bundesbank alemán, en su empeño por salvar al euro de un casi seguro fracaso y desaparición. Este logro tiene un protagonista, Mario Draghi, expresidente del BCE, de quien Pérez (2012), en un artículo periodístico explica lo que sigue

Le bastó arquear una ceja, y un instante después todos corrían como conejos. Apenas un puñado de palabras pronunciadas el jueves por Mario Draghi, presidente del Banco Central Europeo (BCE), funcionaron como un soplo de aire fresco en esa habitación cerrada que es la crisis europea, con los mercados empeñados en dejar la utopía europea en cueros. "El BCE hará todo lo necesario para sostener el euro. Y, créanme, eso será suficiente", dijo a mediodía en Londres. Esa insinuación corrió como la pólvora: la Bolsa española cerró unas horas después con una subida del 6\% (la mayor en dos años) y la prima de riesgo cayó 50 puntos de golpe, con el tipo de interés del bono a 10 años de nuevo por debajo del 7\%, una cifra que a pesar de todo sigue siendo de auténtica pesadilla. En Italia, la otra frontera del euro, las alegrías fueron similares. En el resto de mercados la mejoría fue la tónica general, tras varias jornadas de desagradable estrés. 
Nunca con tan poco el mercado se había movido tanto: ese guiño del Eurobanco vale más que un centenar de planes de ajuste. Es la prueba de que el mercado sabe que Draghi tiene la solución en su chistera. Solo el BCE tiene el poderío necesario. Aunque para ello su presidente tenga que lidiar con la ortodoxia alemana y esa especie de celo mesiánico que ha impedido, hasta ahora, un mayor activismo del banco central.

La armadura de la Unión cruje por los cuatro costados, en especial por el lado de Grecia, serio candidato a dejar el club, y por los de España e Italia, capaces de echar abajo todo el edificio.

Desde luego, hay varios antecedentes que favorecieron las decisiones de Draghi. La misma GD es uno de estos. Antes del BCE, la Fed había hecho lo mismo en EE. UU., y la recuperación tomaba forma. $\mathrm{Y}$ a nivel de la literatura hubo muchas advertencias sobre los tipos fijos en el caso de la UE. En la actualidad, en ocasión del Covid-19, el BCE lleva a cabo un programa de asistencia a los países del euro por un monto de $\$ 755.000$ millones; del que se benefician incluso países como Alemania, pero también los llamados "derrochadores", principalmente España e Italia; y ha dado señales claras de que suministrará "lo que sea necesario" en la eventualidad de más brotes del virus y más confinamientos, como justamente sucede.

Además, una proporción elevada de esta suma se entregará incluso en la forma de transferencias, es decir, sin devolución de los montos concedidos. La Fed, desde lue- go, ha hecho lo propio, y después de un programa billonario en 2020, la nueva Administración en EE. UU. se dispone a buscar la aprobación del Congreso para otro paquete de similares dimensiones en 2021. $\mathrm{Y}$ no se descartan otros paquetes a lo largo de este año.

\section{Caso El Salvador}

¿Qué tiene que ver todo esto con El Salvador? Para ver la relación hay que retroceder un poco en las causas de la GD. La pregunta que hay que hacer es ¿Por qué los bancos centrales practicaron una política de austeridad monetaria en vez de una política monetaria expansiva? Antes de seguir hay que mencionar que al examinar la historia y los números se encuentra que fue sólo después que la política monetaria se flexibilizó -de aquí el relajamiento y la flexibilización cuantitativos- los efectos de la GD sencillamente se revirtieron. $¡ Y$ de forma inmediata! ¡En cada país que arrojó por la ventana la austeridad!

No estamos diciendo que la austeridad sea mala per se. Solo decimos que en el caso de la GD fue una invitación al suicidio. Igual que hoy con el Covid-19. Ahora respondemos la pregunta: los bancos centrales no relajaron la política monetaria porque si hacían lo contario, es decir, si expandían la oferta monetaria, habrían perdido cierta parte de sus reservas en oro, dada su adherencia al patrón oro de la época. Estamos hablando de hace unos 90 años, cuando los países occidentales, los más grandes en su mayoría, habían adoptado unas décadas antes un tipo 
de cambio fijo, el patrón oro en este caso, por el que se dotaba al sistema monetario internacional de una dosis importante de orden, estabilidad y buen funcionamiento general que fueron notables por un período.

Pero aquel orden y estabilidad saltaron por los aires cuando la operación y vigencia del sistema provocó la GD, y la persistencia de la rigidez o falta de flexibilidad en la respuesta monetaria impuesta por el patrón oro solo prolongó la crisis. Autores como Barry Eichengreen, Peter Temin y Ben Bernanke han puesto de manifiesto la culpabilidad del patrón oro en relación con la GD, no sin antes reconocer que un marasmo de aspectos de economía política más que de política económica tuvieron que ver con la crisis.

Entonces, otra vez: ¿Qué tiene que ver esto con El Salvador? El régimen cambiario de El Salvador -tipo de cambio súper fijo a partir de la dolarización, desde 2001- tiene todas las características principales del patrón oro. En particular, el país carece de política monetaria, es decir, para el caso, que no puede aumentar la oferta monetaria mediante la emisión de dólares. La atadura y rigidez que impone el patrón oro ha sido denominada por Eichengreen como una de "grilletes dorados"; en El Salvador puede decirse que la dolarización actúa como una camisa de fuerza -¿dorada?- que impide maniobrar conforme la necesidad actual para financiar el déficit fiscal y los primeros dos componentes del Plan Económico.

Nótese que el país no tiene política monetaria porque no puede emitir dólares y por eso "no puede ir con todo", "cueste lo que cueste", contra la pandemia y sus efectos. Esto también significa que en el país no se pueden aplicar algunas de las lecciones más importantes que se derivan de la GD y que ahora son comunes en el mundo, como cuando se aplicaron en ocasión del New Deal del presidente Roosevelt; se aplicaron en el caso de la GR de 2008/9; y se aplican ahora por la pandemia. Esto es lo que ha prolongado por tanto tiempo la depresión económica en el país, semejante a una bomba que ya lleva dos décadas estallando -recuerde: delincuencia, subempleo y migración.

Al mismo tiempo, la permanencia del tipo de cambio fijo -dolarización- ha impedido el ejercicio de una política cambiaria activa por la que se mantuviera un nivel apropiado de competitividad en las exportaciones de cara a los mercados internacionales, que permitiera un crecimiento decente en vez de las tasas raquíticas que se han registrado. Por esto, la tercera etapa del Plan -crecimiento inclusivo sostenible- es claramente imposible sin un tipo de cambio competitivo. Es decir, el grillete dorado de la economía salvadoreña es el tipo de cambio fijo implícito en la dolarización.

La prioridad del país ahora no es la de reducir el déficit fiscal, sino la de aumentar de forma apremiante su espacio fiscal que por ahora es prácticamente nulo. Esto requiere dejar la dolarización -lo que debe ser claro al lector después de tanta plática sobre el patrón oro- y aprovechar la mayor o menor capacidad que para dinamizar la recuperación estaría disponible una vez pueda emitir 
su propia moneda, sin dejar de lado incluso la posibilidad de una financiación directa del gasto público, ahorrando el pago de intereses, como ha decidido hacerlo el Banco de Inglaterra desde el año pasado para apoyar al Gobierno en su lucha contra el Covid-19 y en la recuperación económica. La Fed hace lo propio, desde la GR y ahora con el Covid-19 financia el gasto del Gobierno con los quantitative easing, con solo apretar un botón con el que se crea el dinero en los montos necesarios y se acreditan a una cuenta del Gobierno.

Ben Bernanke, ex jefe de la Fed, lo explicó así en una famosa entrevista en la que se le preguntó por el origen de los fondos para financiar la flexibilización cuantitativa, y se limitó a contestar "no es dinero de impuestos". 3 De forma parecida, el BCE aprieta un botón para que los países miembros de la Unión Europea, UE, que lo requieran tengan acceso a cientos de millones de euros creados por el BCE, gran parte de los cuales no serán devueltos porque se entregan en calidad de transferencias, por ejemplo, para ayudar a los desempleados y a empresas de todo tamaño, pero especialmente las pequeñas. ¿Y la inflación? La UE tiene un problema serio con la inflación que ya lleva años: es demasiado baja; o, si lo prefiere el lector, el problema no es la inflación sino la deflación acompañada de tasas de interés a veces hasta negativas. Lo mismo pasa con Japón que tiene una deuda de más de 200\% de su PIB y tasas de interés e inflación cerca de $0 \%$.

El lector dirá que se trata de países grandes; que estos lo pueden hacer pero no El Salvador. En realidad, no tiene por qué ser así. La Teoría Monetaria Moderna, TMM, explica que un país con moneda propia puede emitir la cantidad de dinero que necesite sin que esto se traduzca en inflación siempre que existan recursos reales sin utilizar en el proceso productivo. La inflación aparece después del pleno empleo de los recursos, particularmente el trabajo. Ciertamente, los seguidores de la TMM explican que no pueden extender sus resultados a países pequeños, aunque tengan moneda propia, porque a medida que crezca la economía el déficit externo puede crecer y habría que pagarlo con moneda extranjera que el país no puede emitir, y que en general no posee en cantidades suficientes. Esto significa que se podrían presentar algunos cuellos de botella, de los que el déficit externo sería solo uno. El mismo pleno empleo de los recursos sería otro. La literatura parece sugerir que el déficit externo se presentaría antes que el pleno empleo se alcance; en todo caso, existe un umbral: sería interesante averiguar cuánto se puede lograr en términos de reducciones del desempleo, subempleo, migración y delincuencia, y sin que los precios se disparen, antes de que el déficit externo estrangule el proceso de mejoras.

3 Véase Bernanke (2020) para un repaso del "arsenal" del que dispone la Fed, y por extensión, aunque un poco menos, el BCE, para enfrentar crisis como la de la GD y la de la pandemia. 
Tres puntos aquí; siendo el caso que no existe experiencia para ver la aplicación de la TMM en un país pequeño. Primero, ¿qué tal si al disponer de moneda propia y de un tipo de cambio competitivo se inicia un desarrollo exportador importante que permita diferir en el tiempo la aparición de un déficit externo que pudiera lucir amenazante? Segundo, la deflación en el país -a pesar del gasto de alrededor de $\$ 3.000$ millones no presupuestados que ha tenido lugar en 2020, que según el enfoque convencional debió haber desatado una inflación elevada (ver adelante)- demuestra que en la actualidad existen muchos recursos ociosos, especialmente el humano, además de cientos de negocios que han debido cerrar por los confinamientos. Esto significa que existe un trecho relativamente largo que los precios han de transitar antes de que su crecimiento sea una amenaza.

En realidad, los peligros de una inflación o hiperinflación por el gasto expansivo son más bien limitados, dado el proceso deflacionario por el que atraviesa esta economía; cosa que también sucede en Europa y en menor medida en EE. UU.; pero también de forma clara en América Latina donde la inflación anual se ha reducido. En realidad, la deflación es un resultado colateral típico en una crisis como la actual. También ocurrió con mucha fuerza y causó mucho daño en la GD. Por cierto, alrededor de septiembre de 2020, según la CEPAL, las tasas anuales del IPC eran negativas para cuatro econo- mías latinoamericanas: Ecuador (-0.9\%), El Salvador (-0.3\%), y Panamá (-2.4\%), las economías dolarizadas; y Cuba $(-0.3 \%){ }^{4}$

¿Las causas de la deflación? Es sencillo: al igual que en la GD, en el caso de la pandemia se ha registrado una contracción severa de la oferta y demanda agregadas como resultado de la paralización económica en varios frentes. El cierre obligado de negocios y empresas reduce la producción y el empleo y por esto el ingreso de las familias, por lo que deben gastar menos, y si es posible, ahorrar por la incertidumbre. En este entorno, en el que la población gasta menos, los productores y comerciantes suelen verse obligados a bajar sus precios si quieren vender.

Tercero, con la emisión de dinero cabe señalar algunas opciones en cuanto a la inflación. Siguiendo la TMM, esta aparecerá una vez se alcance el pleno empleo de los recursos; existe entonces un umbral. ¿Y qué pasa mientras no se alcanza este umbral? La presencia de un umbral indica que existe un margen de actuación. Su amplitud, desde luego, no se conoce, y en la medida en que no hay experiencias que permitan derivar lecciones para una aplicación afectiva de estas, el problema es uno de naturaleza empírica más que analítica.

Es decir, que solo hay una manera de averiguar lo que pasaría en el país si se ejecutaran estas ideas: llevándolas a la práctica. 
Es posible que una de las medidas que más ansiedad pudieran causar sea la desdolarización y la posterior devaluación que haya de efectuarse según las lecciones aprendidas de la GD. Teniendo en cuenta que la situación actual en el país (tipo de cambio fijo y deflación) y en el mundo es una muy parecida a la de la GD, se puede tomar nota del punto de vista de Bernanke (2002):

... ha habido momentos en que la política cambiaria ha sido un arma eficaz contra la deflación. Un ejemplo sorprendente de la historia de Estados Unidos es la devaluación de Franklin Roosevelt del 40 por ciento del dólar frente al oro en 1933-34, impulsada por un programa de compra de oro y creación de moneda nacional. La devaluación y el rápido aumento de la oferta monetaria que permitió puso fin a la deflación de Estados Unidos de manera notablemente rápida. En efecto, la inflación de precios al consumidor en los Estados Unidos, año tras año, pasó de -10,3 por ciento en 1932 a -5,1 por ciento en 1933 a 3,4 por ciento en 1934. La economía creció fuertemente, y por cierto, 1934 fue uno de los mejores años del siglo para el mercado de valores. Si nada más, el episodio ilustra que las acciones monetarias pueden tener efectos poderosos en la economía, incluso cuando la tasa de interés nominal está en cero o cerca de cero, como sucedía en el momento de la devaluación de Roosevelt. (Pg. 7)

Sin duda, el amor por la inflación puede llegar a ser fuerte ... especialmente si hay una deflación vigente; porque esta suele acompañarse de un séquito que incluye fuertes caídas en la producción, el empleo, y los salarios; y, dependiendo de su severidad, hasta de crisis bancarias, por varios factores, entre los que destacan los aumentos de la morosidad y la caída en la demanda de créditos.

Más específicamente, la deflación en el país se nota de las medidas del IPC: el boletín mensual de la DIGESTYC de diciembre de 2020 , pg. 7 , permite ver que la inflación punto a punto (enero 20/enero 19, ..., diciembre $20 /$ diciembre 19) fue negativa todos los meses de 2020. Sin embargo, aunque esta deflación no es severa, se sabe que las caídas en la producción y el empleo lo son; y los efectos en el sistema financiero incluyen caídas importantes en el crecimiento del crédito a lo largo de 2020, como se nota de Cantizzano e Ibarra (2021).

\section{Conclusiones}

De lo expuesto, es posible caracterizar la situación de la economía salvadoreña como sigue. Por un lado, hay un déficit fiscal con pagos fuertes en deuda de corto plazo para lo cual se ha de recurrir a más endeudamiento de corto plazo. Por otro lado, se necesita financiar las primeras dos etapas del Plan Económico antes señalado, dado su carácter de emergencia, las que incluyen 1) el apoyo al sistema de salud, 2) un programa de empleo, y 3) un programa para la recuperación. Entonces, se han identificado cuatro necesidades financieras que no admiten demora.

¿Cuál es la más crítica? En realidad, las cuatro son críticas, y el déficit fiscal es solo 
una de ellas. De las lecciones aprendidas de la GD y la GR puede verse que los países en general han hecho a un lado las preocupaciones por el déficit fiscal y se han abocado a la solución de los problemas de la salud, el empleo y la recuperación económica. Pero en el país no hay recursos para atender ninguna de estas necesidades. Los recursos que puedan obtenerse del endeudamiento externo con seguridad no serían suficientes dada la calidad que como sujeto de crédito en el exterior tiene el país.

Se sabe de esfuerzos de algunas agencias internacionales para que países del centro apoyen a tantos que como el nuestro no cuentan con lo que se necesita. Se sabe de esfuerzos de la nueva Administración en EE. UU. relacionados con la lucha contra la corrupción en el Triángulo Norte y la eliminación de las causas que impulsan la migración hacia aquel país. Ambas, sin embargo, aunque parecieran cercanas en el tiempo, por ahora están llenas de mucha incertidumbre en cuanto a la posibilidad de que sean verdaderas soluciones.

Pero hay otra opción, la dada por la Teoría Monetaria Moderna, en la que un Gobierno puede financiar cualquier monto de gasto público siempre que haya suficientes recursos reales ociosos y disponibles que permitan prevenir la inflación, cosa que se cumple en el país, la mano de obra especialmente, dado el nivel de desempleo causado por los confinamientos, y la deflación, que se explica por la reducción sustancial de la demanda agregada.
En el caso de la TMM se recuerda que existe un umbral o margen de actuación cuya amplitud se desconoce pero que puede ampliarse dependiendo de una variedad de factores. ¿Valdrá la pena hacer el intento? Creemos que sí, principalmente porque no vemos otras opciones, en el contexto de lo que puede hacer el Gobierno de forma más o menos rápida y directa, para encarar los cuatro problemas señalados. Solo que la TMM no tiene sentido y es sencillamente inconsistente con la dolarización.

Desde luego, el lector informado que ha oído de la TMM puede preocuparse porque personajes de la talla de Paul Krugman, Sebastián Edwards, Kenneth Rogoff y Carmen Reinhart la hayan ridiculizado una y otra vez. Más allá de señalar que cada una de sus observaciones ha tenido la respuesta correspondiente hay que destacar lo siguiente: 1) una razón para el ataque a veces feroz contra la TMM es que su estudio ha cobrado una relevancia increíble con la pandemia y las lecciones derivadas de la GD ante la posibilidad que plantea de, dadas ciertas condiciones, financiar las necesidades de recursos con la impresión de dinero sin preocuparse por el déficit fiscal ni la deuda; y 2) más allá de los pleitos cada vez más sonados entre economistas ortodoxos y los que prefieren la TMM, los hechos muestran claramente que, sea que lo reconozcan o no, los países están siguiendo la prescripción de la TMM al gastar sin mayor preocupación por el déficit fiscal y la deuda. Recuérdelo, del déficit fiscal y la deuda nos ocuparemos "el día después". 
En el proceso de ampliación del espacio fiscal, uno de los primeros pasos es el de eliminar el tipo de cambio fijo de la dolarización. Si lo desea, el lector puede repasar nuestra discusión anterior sobre el papel del tipo de cambio fijo del patrón oro en la GD -note que la causó y la prolongó hasta que los países repudiaron el patrón oro-; observe que su análogo en El Salvador de hoy es el tipo de cambio super fijo que impone la dolarización; ${ }^{5}$ y vea que el tipo de condiciones para que funcione -una fuerte dosis de cooperación en el sistema financiero internacional por la que países superavitarios proporcionan reservas a los deficitarios- es algo utópico por ahora. La práctica internacional en este tema es contundente. La gran mayoría de países desarrollados y emergentes tienen tipos de cambio flotantes -v.gr.: EE. UU., Japón, UE con el euro, etc.-; o manipulados -como China y Brasil-; pero no fijos.

Con todo, una cosa es segura. Más allá de la manera en que estos problemas evolucionen en el futuro, esta discusión ha puesto de manifiesto que el déficit fiscal es solo uno de los problemas que requieren atención desde ayer, pero que, dependiendo de la perspectiva del tomador de decisiones, hasta pudiera relegarse en el tiempo en relación con otros que pueden ser más inminentes. Por ejemplo, algunos observadores pueden razonar que, en vez de cancelar la deuda pública con los bancos, los recursos escasos rendirían un retorno social mucho mayor si se destinan hacia la población desempleada, un fortalecimiento inaplazable del sistema nacional de salud y la compra de vacunas, utilizando el mecanismo del "dinero de helicóptero"; al menos por un tiempo; y "el día después" platicamos de una reestructuración del déficit fiscal.

¿Cuál compromiso es más fuerte, el que se tiene con los bancos o el que se tiene con la población? De aquí es claro que el déficit fiscal no es el principal problema del país. Claro, esta es una solución tipo "parche" y a medias de los problemas mencionados, $y$ no es sostenible. A menos que haya un crecimiento económico fuerte y sostenido que provea los recursos necesarios. Pero en el corto plazo -un período que fue relevante en la GD y lo es más con la pandemia porque hay gente que está muriendo y no puede esperar a que se alivie el déficit fiscal- puede lucir de otra manera.

Entonces, para finalizar, "a grandes males grandes remedios". Esta breve consideración muestra que, en realidad, los problemas del endeudamiento y el déficit fiscal en el país deben verse como una manifestación y un síntoma de problemas mucho mayores que aquejan a la economía salvadoreña ya por muchos años. Los problemas fiscales tendrán una solución efectiva cuando sean removidos los obstáculos que impiden el logro del crecimiento inclusivo; no pueden verse en el entorno meramente fiscal, sino

5 Otros resultados de la dolarización en la economía salvadoreña, especialmente en la pobreza, la desigualdad y el crecimiento, pueden verse en González (2020). 
en uno mucho mayor: la erradicación de la pobreza, de la desigualdad y el logro del crecimiento económico.

Los problemas del país no se pueden manejar con acciones superficiales y cosméticas, de carácter micro y de corto plazo. De hecho, la crisis actual ha sido aprovechada por varios países para llevar a cabo transformaciones de gran calado en sus economías. En el país debe hacerse lo mismo, comenzando con la desdolarización, lo cual no tiene que ser catastrófico si se aseguran las condiciones necesarias para llevar a cabo un proceso ordenado. Si algo amable puede verse del Covid-19 es la oportunidad que brinda para llevar a cabo reformas profundas. Es probable que si no se hacen ahora no se hagan nunca.

\section{Referencias}

1 Barría, Cecilia (2020), "Por qué hay una inflación tan

6 DIGESTYC (2021), Boletin No. 132. IPC diciembre 2020. DIGESTYC.

baja en América Latina y qué dice de la economía de la región". BBC News Mundo del 11 de enero.

7 Eichengreen, Barry J. (2010), "The Breakup of the Euro Area". NBER Chapters, in: Europe and the Euro, pp. 1151. National Bureau of Economic Research, Inc.

2 Bernanke, Ben S. (1995), "The Macroeconomics of the Great Depression: A Comparative Approach". Journal of Money, Credit, and Banking, Vol. 27, No. 1 (February 1995). The Ohio State University Press.

3 Bernanke, Ben S. (2002), "Deflation: Making Sure "It" Doesn't Happen Here". Remarks by Governor Ben S. Bernanke Before the National Economists Club, Washington, D.C. November 21, 2002. The Federal Reserve Board.

4 Bernanke, Ben S. (2020), "The New Tools of Monetary Policy". American Economic Association Presidential Address. January 4, 2020.

8 Eichengreen, Barry J. and Peter Temin (2010), "Fetters of Gold and Paper". NBER Working Paper16202.

9 González O., Mauricio (2020), "El Salvador: Macroeconomía de la Pobreza, la Desigualdad y el Crecimiento". Centro de Investigaciones en Ciencias y Humanidades, Universidad Dr. José Matías Delgado. San Salvador.

10 Margo, Robert A. (1992), "Employment and unemployment in the 1930s". NBER Working Paper 4174. NBER.

11 Pérez, Claudi (2012), "El BCE hará lo necesario para sostener el euro". El País, de 26 de julio de 2012. 